\title{
Self-rated ability to follow instructions for four mental states described in yoga texts
}

\author{
Raghavendra Bhat Ramachandra ${ }^{1}$, Shirley Telles ${ }^{2, *}$, Nagendra Rama Rao Hongasandra ${ }^{1}$ \\ ${ }^{l}$ Division of Yoga and Life sciences, Swami Vivekananda Yoga Anusandhana Samsthana, Bengaluru, India; ${ }^{2}$ Patanjali Research \\ Foundation, Patanjali Yogpeeth, Haridwar, Uttarakhand 249408, India
}

\begin{abstract}
There were no studies available measuring the ability to follow instructions for meditation. Hence, the present study was planned to assess the ability to follow instructions for the four mental states viz., cancalata (random thinking), ekagrata (non-meditative concentration), dharana (focused meditation) and dhyana (defocused meditation or effortless meditation) described in yoga texts. Sixty male volunteers with ages ranging from 18 to 31 years (group mean age \pm S.D., $22.78 \pm 2.73$ ) participated in the study. They were assessed using a visual analog scale immediately after each of the four states on four different days. The results showed that following dharana, scores on the visual analog scale were significantly lower compared to those related to cancalata, ekagrata and dhyana. Hence, dharana is the most difficult of the four states.
\end{abstract}

Keywords four mental states, cancalata, ekagrata, dharana, dhyana, visual analog scale

\section{INTRODUCTION}

The practice of meditation has become increasingly popular all over the world in the last few decades. Positive physiological and psychological changes following meditation are supported by a number of research studies (Cahn and Polich, 2006; Keng et al., 2011). However, the results are distinct and different. This may be due to differences in the methods and principles of the practice of meditation.

Recently, there was a report which described three broad categories of meditation techniques and their EEG patterns (Travis and Shear, 2010). The three categories were (i) focused attention, which involves voluntary and sustained attention on a chosen object, (ii) open monitoring meditation in which there is non-reactive monitoring of the moment-to-moment content of the experience, and (iii) automatic self-transcending, which includes techniques intended to transcend the practitioner's own activity. All these modern derived meditation techniques are supposed to fit in the above-mentioned categories. Specific meditation techniques may be more effective for certain persons based on their psychological characteristics.

In Patanjali's Yoga Sutras (PYS), ancient Indian yoga text (Circa 900 B.C.), there are two meditative states described (Taimini, 1986). Sage Patanjali lays out eight stages of yoga in Yoga Sutras (aphorisms). These are (i) and (ii) yamas and niyamas (rules for good conduct), (iii) asanas (physical postures), (iv) pranayamas (voluntarily regulated breathing), (v) pratyahara (withdrawal, particularly from external sensations), (vi) dharana (focused meditation), (vii) dhyana (defocused meditation or effortless meditation), and (viii) samadhi (an experience of transcendence or ultimate realization). The sixth and seventh stages are pertaining to meditation. Dharana

\footnotetext{
"Correspondence: Shirley Telles

E-mail: shirleytelles@gmail.com

Received June 5, 2012; Accepted August 23, 2012; Published August

31,2012

doi: http://dx.doi.org/10.5667/tang.2012.0023

(C)2012 by Association of Humanitas Medicine

TANG / www.e-tang.org
}

(focused meditation), is defined as confining the mind within a limited mental area (PYS 3.1). The next stage is dhyana (effortless meditation or defocused meditation) (PYS 3.2) which is characterized by the uninterrupted flow of the mind towards the object chosen for meditation. Dharana and dhyana may be considered as the last two of four stages, which form a continuum in the process and practice of meditation. The first two stages are described in another ancient Indian text the Bhagavad Gita (Sarasvati and Swami, 1998). The first stage is cancalata, which is a stage of random thinking. The second stage is ekagrata, during which the attention is directed to a series of associated thoughts. The concept of the four mental states described in yoga texts is schematically presented in Fig. 1 .

A study was conducted on 30 volunteers to assess the changes in these mental processes in brainstem auditory-evoked potentials (Kumar et al., 2010). The peak latency of wave $\mathrm{V}$ increased significantly during the dharana, ekagrata and cancalata sessions, but there was no change during the practice of dhyana. The findings suggest that dhyana practice alone does not delay auditory transmission at the level of the brainstem, showing the effectiveness dhyana has over other processes. In another study, mid-latency auditory-evoked potentials were assessed in 60 participants during the four mental states (Telles et al., 2012). The results showed prolongation in the latencies of $\mathrm{Na}$ and $\mathrm{Pa}$ waves during meditation (dhyana), suggesting that auditory information transmissions at the levels of the medial geniculate and primary auditory cortex were delayed. Similarly, performances in a cancellation task studied in 70 normal, healthy male volunteers showed a significant increase after dharana and a decrease after cancalata, suggesting better attention after dharana (Kumar and Telles, 2009). There were no changes in dhyana and ekagrata.

The concept of an analog scale to assess subjective feelings was described early in 1921 (Hayes and Patterson, 1921). Lately, a visual analog scale has been widely used in rating the subjective feelings (Aitken, 1969). The advantages include it is 
Multiple subject - Multiple thinking

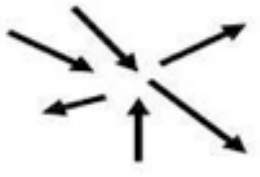

\section{Cancalata}

(Random thoughts)

\section{Single subject - Multiple thoughts}

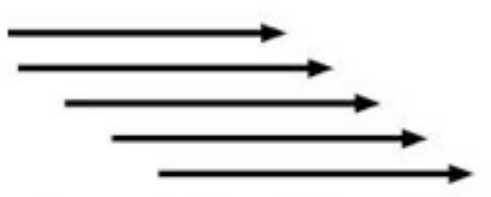

Single thought -

Effortful focusing

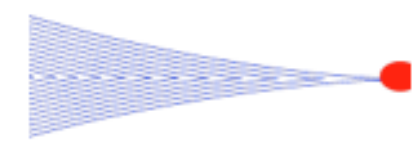

Dharana

(Focused meditation)
Ekagrata

(Non-meditative concentration)

\section{Single thought - \\ Effortless defocusing}

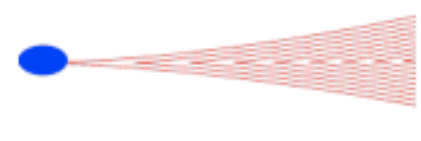

\section{Dhyana}

\section{(Defocused meditation or effortless meditation)}

Fig. 1. Schematic representation of four mental states described in yoga texts.

easy for the subject to grasp, quick to fill out and score, and as the subject is not restricted to direct quantitate terms, one can make a fine discrimination. In an early study on the effect of meditation on shooting performance, a visual analog scale was used to assess the experience of tension during shooting (Solberg et al., 1996). In another study, a visual analog scale was used to assess global well-being, pain, sleep, fatigue, and tiredness upon awakening in fibromyalgia patients before and after participation in a stress-reduction cognitive-behavioral treatment program (Don et al., 1994). Recently, in a study on the effects of yoga on the quality of life in cancer patients, their satisfaction levels related to the yoga program were evaluated using a visual analog scale (Ulger, 2010).

However, there have been no studies available measuring the ability to follow instructions for meditation. Hence, the present study was planned to assess the ability to follow instructions for the four mental states (cancalata, ekagrata,

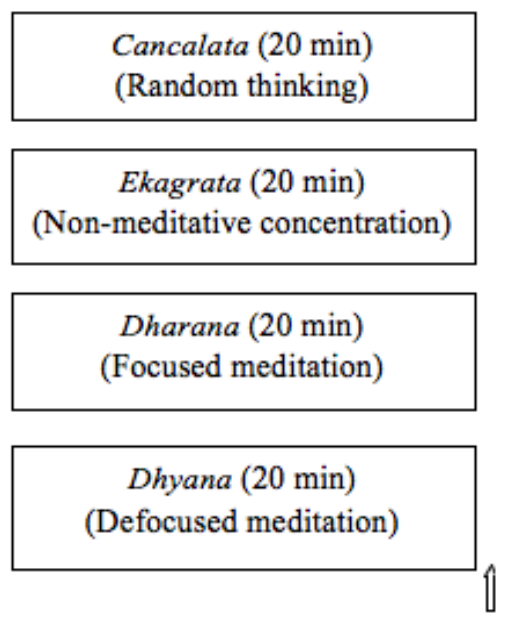

Assessment - VAS

Fig. 2. Schematic representation of the design. dharana, and dhyana) described in yoga texts.

\section{MATERIALS AND METHODS}

\section{Participants}

Sixty male volunteers with ages ranging from 18 to 31 years (group mean age \pm S.D., $22.78 \pm 2.73$ ) were recruited to the study. All of them were of normal health based on a routine case history and clinical examination. They were all students at a yoga University in South India. They had a minimum of six months experience in meditation (group average experience \pm S.D., $20.95 \pm 14.21$ months). Apart from their prior experience of meditation on $\mathrm{Om}$, they were given a three-month orientation program under the guidance of an experienced meditation teacher. Male volunteers alone were selected as their mental state is known to vary with the phases of the menstrual cycle in females (Little and Zahn, 1974). All participants expressed their willingness to participate in the experiment, and the project was approved by the institution's ethics committee. The study protocol was explained to the subjects and their signed consent was obtained.

\section{Design}

Assessments were made on four different days, which were not necessarily on consecutive days, but at the same time of the day. The allocation of participants to the four sessions was random using a standard random number table. Two of them were meditation sessions viz., dharana and dhyana; whereas the other two were non-meditation sessions viz., ekagrata and cancalata. Instructions for all four sessions were played from a compiled audio CD. The duration of all the four sessions was 20 min. A visual analog scale was given immediately after the session. The study design has been schematically presented in Fig. 2. 


\section{$\vdash$ \\ $\uparrow$ Worst possible}

\section{Could not practice as per instructions}

Fig. 3. Visual analog scale.

\section{Interventions}

Throughout all the sessions participants sat cross legged and kept their eyes closed following the pre-recorded instructions for a period of $20 \mathrm{~min}$.

Cancalata (Random thinking)

Participants were asked to allow their thoughts to wander freely as they listened to a compiled audio CD consisting of brief periods of conversation, announcements, advertisements and talks on diverse topics recorded from a local radio station transmission. All these conversations were not connected and could induce the state of random thinking.

\section{Ekagrata (Non-meditative concentration)}

Participants listened to a pre-recorded lecture on meditation. This was not about meditation on the Sanskrit syllable Om, but about meditation, in general. This was supposed to induce a state of non-meditative concentration.

Dharana (Focused meditation)

Participants were asked to open their eyes and gaze at the syllable 'Om' as it is written in Sanskrit. During this time, guided instructions required them to direct their thoughts to the physical attributes of the syllable (i.e., the shape and color), and then to close their eyes and continue to visualize the syllable mentally.

Dhyana (Effortless meditation or defocused meditation)

During this session participants were instructed to keep their eyes closed and dwell on the Om picture without any effort, particularly on the subtle (rather than physical) attributes and connotations of the syllable. This involved the effortless chanting of Om, bringing about the effect of defocusing.

\section{Assessments}

A Visual Analogue Scale (VAS) is an instrument that tries to measure a characteristic or attitude that is believed to range across a continuum of values and cannot easily be directly measured (Wewers and Lowe, 1990). A visual analogue scale is a horizontal line, $10 \mathrm{~cm}$ in length, anchored by word descriptors at each end, as illustrated in Fig. 3. Immediately after the session, participants were asked to put a mark on the line which represents how much they were able to follow the instructions for the four mental states.

\section{Data analysis}

Statistical analysis was done using SPSS (Version 16.0). Repeated measured analysis of variance (ANOVA) was performed with one 'within subjects' factor, i.e., sessions: cancalata, ekagrata, dharana, and dhyana. This was followed by a post-hoc analysis with a Bonferroni adjustment for multiple comparisons between the mean values of different sessions.

\section{Could practice as per instructions}

\section{RESULTS}

The group mean values \pm SD for cancalata, ekagrata, dharana and dhyana are given in Table I. Repeated measures of the analysis of variance (ANOVA) showed significant differences between sessions $[F=31.04, d f=(2.46,145.13)$, Huynh-Feldt epsilon $=0.820, p<0.001]$. Post-hoc analyses with a Bonferroni adjustment were performed to see the changes between the sessions. Following dharana, scores on the visual analog scale were significantly lower compared to those for cancalata $(p<0.001)$, ekagrata $(p<0.001)$, and dhyana $(p<$ 0.001).

\section{DISCUSSION}

The present study was conducted to assess the self-rated ability to follow the instructions to achieve the four mental state's viz., cancalata, ekagrata, dharana and dhyana using a visual analog scale. The results showed that following dharana, scores on the visual analog scale were significantly lower compared to those for cancalata, ekagrata and dhyana.

A study has shown the brain areas involved in FA (Focused Attention) and OM (Open Monitoring) meditations are distinct and different (Lutz et al., 2008). FA meditation improves the practitioner's ability to sustain attention on a particular object for prolonged periods. During FA meditation, functional magnetic resonance imaging (fMRI) has shown activation in the brain regions involved in monitoring, engaging attention and attentional orienting. In contrast, OM meditation has shown activation in the brain regions implicated in monitoring, vigilance and disengaging attention from stimuli which could distract attention from the experience at that moment. Hence, it is very much evident that the brain areas involved in these four mental states are different.

Dharana involves mental visualization and intense focusing on the Sanskrit syllable Om. Some people may have difficulties in mentally visualizing the symbol for a long time. Also, participants might have had difficulties in keeping the intense focus on the syllable Om for $20 \mathrm{~min}$. The average attention span in healthy adults is between $15-20 \mathrm{~min}$. Dharana requires focused attention; whereas dhyana, ekagrata and cancalata do not need focused attention.

The usefulness of practicing dharana is well known. Focused attention on a single object removes cancalata and takes us to a higher state than ekagrata by moving the mind from multiple thoughts to a single thought of a visual picture as 'Om' used here. However, according to yoga, it is well known that dharana involves intense effort to keep the focus on the given object for longer durations. It causes fatigue as it drains away the energy. However, it is useful for removing drowsiness

Table 1. Scores on visual analog scale following four mental states

\begin{tabular}{lcccc}
\hline Sessions & Cancalata & Ekagrata & Dharana & Dhyana \\
\hline Mean \pm S.D. & $8.08 \pm 0.50$ & $8.07 \pm 0.56$ & $7.45 \pm 0.65^{* * *}$ & $8.22 \pm 0.70$ \\
\hline${ }^{* * *}$ Comparing dharana with cancalata, ekagrata, and dhyana & sessions shows significant differences with all three $(p<0.001$ for each).
\end{tabular}


(Tamas) and inducing alertness.

Hence, traditionally (PYS 3.2) dharana is used for a short duration, about a minute and then one proceeds to perform dhyana by making the mind to stay on a single thought effortlessly. The five main features of the dhyana state are single thought, effortlessness, slowness, wakefulness and expansiveness. A long duration of meditation helps one to gain mastery over the mind and leads to a state of superconsciousness called samadhi (PYS 3.4).

In summary, the study has shown that, (i) cancalata and ekagrata and dhyana can be done with equal ease, and (ii) dharana is the most difficult state compared to the cancalata, ekagrata and dhyana states.

\section{ACKNOWLEDGEMENTS}

The authors gratefully acknowledge the funding from the Indian Council of Medical Research (ICMR), Government of India, as part of a grant (Project No. 2001-05010) towards the Center for Advanced Research in Yoga and Neurophysiology (CAR-Y\&N).

\section{CONFLICT OF INTEREST}

The authors have no conflicting financial interests.

\section{REFERENCES}

Aitken RC. Measurement of feelings using visual analogue scales. Proc R Soc Med. 1969;62:989-993.

Cahn BR, Polich J. Meditation states and traits: EEG, ERP, and neuroimaging studies. Psychol Bull. 2006;132:180-211.

Goldenberg DL, Kaplan KH, Nadeau MG, Brodeur C, Smith S, Schmid CH. Controlled Study of a Stress-Reduction, Cognitive-Behavioral Treatment Program in Fibromyalgia. J Musculoskeletal Pain. 1994;2:53-66.

Hayes MHS, Patterson DG. Experimental development of the graphic rating method. Psychol Bull. 1921;18:98-99.

Keng SL, Smoski MJ, Robins CJ. Effects of mindfulness on psychological health: a review of empirical studies. Clin Psychol Rev. 2011;31:1041-1056.

Kumar S, Nagendra HR, Naveen KV, Manjunath NK, Telles S. Brainstem auditory-evoked potentials in two meditative mental states. Int J Yoga. 2010;3:37-41.

Kumar S, Telles S. Meditative states based on yoga texts and their effects on performance of a cancellation task. Percept Mot Skills. 2009;109:679-689.

Little BC, Zahn TP. Changes in Mood and Autonomic Functioning During the Menstrual Cycle. Psychophysiology. 1974;11:579-590.

Lutz A, Slagter HA, Dunne JD, Davidson RJ. Attention regulation and monitoring in meditation. Trends Cogn Sci. 2008;12:163-169.

Sarasvati M, Swami G. Bhagavad Gita. (Calcutta, India: Advaita Ashrama), 1998.

Solberg EE, Berglund KA, Engen O, Ekeberg O, Loeb M. The effect of meditation on shooting performance. Br J Sports Med. 1996;30:342-346.

Taimini IK. The science of yoga: The Yoga-sūtras of Patañjali in Sanskrit with Transliteration in Roman, Translation and Commentary in English. (Madras, India: The Theosophical Publishing House), 1986.

Telles S, Raghavendra BR, Naveen KV, Manjunath NK, Subramanya P. Mid-Latency Auditory Evoked Potentials in 2 Meditative States. Clin EEG Neurosci. 2012;43:154-160.

Travis F, Shear J. Focused attention, open monitoring and automatic self-transcending: categories to organize meditations from Vedic, Buddhist and Chinese traditions. Conscious Cogn. 2010;19:1110-1118.

Ulger O, Yağli NV. Effects of yoga on the quality of life in cancer patients. Complement Ther Clin Pract. 2010;16:60-63.

Wewers ME, Lowe NK. A critical review of visual analogue scales in the measurement of clinical phenomena. Res Nurs Health. 1990;13:227-236. 